\title{
A CRECHE E AS MULHERES TRABALHADORAS NO BRASIL*
}

\section{DAYCARE CENTERS ANI 3 WORKING WOMEN IN BRAZI L}

\author{
Maria Cecilia Focesi Pelicioni ${ }^{1}$
} Nelly Martins Ferreira Candeias ${ }^{2}$

PELICIONI, M.C.F.; CANDEIAS, N.M.F. A Creche e as Muiheres Trabalhadoras no Brasil. Rev. Bras. Cresc. Desenv. Hum., São Paulo, 7(1) 1997.

Resumo: Esse trabalho apresenta uma revisão bibliográfica sobre o desenvolvimento da creche enquanto instituição, mostrando o papel que essa vem desempenhando no decorrer da história e principalmente no Brasil. Discute as dificuldades pelas quais a creche tem passado especialmente no que se refere à capacitação dos funcionários. na maioria constituido por mulheres.

Palavras-clave: creche, capacitação, mulher trabalhadora.

\section{HISTÓRICO}

A primeira creche de que se tem notícia surgiu em 1770 e foi fundada pelo sacerdote Oberlin, na aldeia de Vosgues au Ban de la Roche na França. Teve por finalidade dar assistência aos lactentes de famílias campesinas com longa jornada de trabalho. Nessa mesma época, outras creches foram sendo organizadas, gradativamente, em centros industriais na Grã-Bretanha e demais países europeus. Em 1846, havia em Paris, 14 creches particulares, dirigidas por congregações religiosas ou entidades filantrópicas. Durante quase um século, as creches tiveram a função de combater a pobreza e a mortalidade infantil, adotando para isso uma perspectiva médico-higienis$\operatorname{ta}^{10,18.21}$

Nos Estados Unidos, em 1941, durante a Segunda Grande Guerra, criaram-se muitas creches para os filhos dos empregados na indústria de guerra. No final da guerra, contudo, com a retirada do apoio governamental, decresceram as vagas então disponíveis ${ }^{11.13,15,18}$.
Na década de 50, principalmente nos Estados Unidos e na Europa, começou-se a questionar o papel das creches por considerá-las fontes da desadaptação de crianças privadas do convívio materno. Teóricos como SPTIZ ${ }^{28}$, BOWLBY ${ }^{3}$, AINSWORTH ${ }^{1}$, entre outros, realizaram estudos de natureza psicoanalítica, mostrando a importância da relação da criança com sua mãe, como pressuposto básico ao desenvolvimento emocional infantil e às relações sociais na idade adulta ${ }^{10,11,19}$.

A partir de 1960, resultados de algumas pesquisas ${ }^{6,11,17,20}$ demonstraram que as creches não eram tão prejudiciais como se afirmara anteriormente. Na América do Norte, movimentos feministas passaram a lutar pelo direito de atendimento a todas as mulheres independente de necessidades de trabalho e classe social ${ }^{10,20}$.

A história das creches, em vários países, parece evidenciar que os determinantes da expansão das redes públicas de creche têm sua origem em decisões alheias às necessidades das crianças. Refletem políticas que apoiam ou o cerceamento ou o incentivo ao trabalho materno ${ }^{19}$.

Capítulo de Tese de Doutorado apresentada à Faculdade de Saúde Pública da Universidade de São Paulo em 1995.

Profa. Dra. do Depto. de Prática de Saúde Pública da Faculdade de Saúde Pública - USP.

2 Profa. Titular do Depto. de Prática de Saúde Pública da Faculdade de Saúde Pública - USR End.: Av. Dr. Arnaldo, 715, Depto. de Prática de Saúde Pública, Térreo - São Paulo - SP - CEP: 01246-904 - Tel. (011) 3066-7743. 
Atualmente, a creche é considerada como um Direito da Criança, em termos educativos, e não apenas como substitutivo dos cuidados maternos. É vista como um lugar que contribui para a educação e socialização da criança ${ }^{10}$.

\section{NO BRASIL}

Foi na década de 20 que as primeiras creches foram introduzidas nas empresas brasileiras. A primeira creche industrial foi a da Fiação Maria Zélia, de Jorge Street criada em São Paulo em $1920^{6}$. Operários de indústrias paulistas reivindicaram uma série de vantagens entre as quais creches para seus filhos. Protestavam ao mesmo tempo contra suas precárias condições de vida e de trabalho: jornadas excessivas, insalubridade, inexistência de assistência médica, falta de moradia ${ }^{15}$.

Na década de 40, com a Consolidação das Leis do Trabalho, estabeleceu-se a obrigatoriedade de manutenção de creches em empresas privadas que empregassem mão-de-obra feminina com 30 ou mais mulheres com mais de 16 anos de idade, (Art. $1^{\circ}$ da Portaria DNSHT n ${ }^{\circ} 1$ de 15 de janeiro de 1989), em idade fértil, portanto, para filhos de até 6 meses, protegendo, com isso, apenas a amamentação do bebê. Durante muito tempo, contudo, a legislação, além de não ser respeitada por grande parte do empresariado, foi praticamente desconhecida pelos trabalhadores a quem se destinava. O Estado considerava-se desobrigado de qualquer iniciativa dessa natureza ${ }^{19}$.

As primeiras creches municipais apareceram na década de 60, com construção e manutenção garantidas pela Prefeitura Municipal de São Paulo, mas com o gerenciamento feito por entidades particulares, responsáveis estas, também, pela orientação do trabalho junto às crianças. Segundo NOGUEIRA ${ }^{14}$, levantamento realizado em 1967 revelou que das 93 indústrias do Município de São Paulo, com mais de 100 empregados, somente 31 (33,3\%) dispunham de creche. As creches de responsabilidade exclusiva da Prefeitura (creches diretas) forain instituídas na década de 70 , mostrando-se um empreendimento de elevado custo. Na década de 80, passou-se a defender novamente o convênio com entidades particulares, já que o atendimento se restringia apenas à pequena parte da demanda. Em 1984, só 5,9\% das crianças de 6 anos ou menos e de famílias de até 5 salários minimos eram atendidas na cidade de São Paulo ${ }^{15}$.

A expansão de creches municipais deveuse principalmente ao grande cresciinento populacional (principalmente de pessoas com baixa renda), ao aumento da industrialização e do setor de serviços, à integração da mão-de-obra feminina na população economicamente ativa e, também, ao Movimento de Luta por Creches, em resposta à resolução do I Congresso da Mulher Paulista, ein $1979^{6,15,17,19}$.

\section{PAPEL DA CRECHE}

A creche é considerada como uma estrutura de educação e de assistência, cujas atividades se dirigem, quase que exclusivamente, à população de baixa renda e, conseqüentemente, com menor acesso a benefícios sociais. É uma organização dinâmica, onde interagem crianças usuárias e trabalhadores, com direito a uma identidade própria, peculiar e diferente do espaço escola ${ }^{26}$.

De acordo com documentos da Secretaria da Família e Bem Estar Social da Prefeitura Municipal de São Paulo (FABES), de 1991, apesar de o direito à creche ser universal, hoje, por causa dos recursos disponíveis serem limitados, são aceitas para admissão apenas as crianças de condição economicamente precária (renda familiar de 4 salários minimos ou menos, prioritariamente), na tentativa de garantir-lhes condições qualitativamente diferentes de inserção na sociedade. “A FABES vem construindo uma política de assistência, entendida como forma de fornecimento de bens e serviços à população deles excluida, em decorrência da organização econômica e política da sociedade" (p. 2). A criança deve "ser considerada como criança, sem marcas de discriminação, capaz de desenvolver sua autonomia, de construir-se enquanto pessoa, de conhecer, reconhecer e transformar a realidade à sua volta, inserindose em seu grupo social de maneira consciente e livre, e tratada como cidadã de direitos e não de favores"24 (p. 10).

A programação psicopedagógica proposta pela FABES (antiga SEBES - Secretaria do Bem Estar Social da Prefeitura Municipal de São Paulo), para as Creches de São Paulo, tem como objetivo "desenvolver a consciência crítica e criativa da criança, possibilitando sua inserção na sociedade, como agente e sujeito de sua transformação"26 (p. 14).

A programação do setor saúde procura “criar condições para o desenvolvimento de ações de promoção, manutenção e recuperação da saúde, prevenção de doenças e educação em saúde da população participante dos diferentes programas, crianças usuárias, familiares e trabalhadores da creche, mediante trabalho conjunto com outros órgãos públicos e privados. A educação em saúde dá-se principalmente pela capacitação de pessoal, atuação junto a grupos sociais, inscritos ou não nas 
entidades, e por meio de discussão e encaminhamento de questões ligadas à saúde"26 (p. 4).

A FABES pretende que, por ter um caráter educativo e assistencial, a creche seja considerada como um espaço de promoção de saúde e prevenção de doenças, que envolva também as famílias das crianças. Entende saúde como "resultatado das condições de alimentação, habitação, transporte, saneamento, lazer, educação, distribuição de renda e acesso aos serviços de saúde e, sobretudo, como resultado das formas de organização social da produção e da apropriação de bens e serviços em uma determinada sociedade" (8 $8^{\text {a }}$ Conferência Nacional de Saúde, 1986, p. 2) ${ }^{8}$. Reconhece que a saúde depende de fatores orgânicos (características individuais), de relações interpessoais de afetividade e de capacidade individual de adaptação a diferentes situações. Propõe, portanto, que a saúde das crianças seja compreendida como um processo dinâmico, envolvendo aspectos biológicos e mentais, em interação com o meio familiar, social e com o meio ambiente ${ }^{25}$.

As ações de saúde devem, segundo a Secretaria, ser planejadas visando não só a dimensão individual mas, também, a coletividade da creche e da família, mediante articulação e integração com vários recursos de saúde da região. Considera fundamental que os conhecimentos sobre saúde atinjam a equipe da creche, as crianças, os pais e a comunidade em geral. Contudo, segundo HADDAD ${ }^{11}$, desde sua origem, a creche tem sido percebida como uma instituição emergencial, instável e temporária, em decorrência da precariedade e insuficiência de recursos, má qualidade de atendimento, falta de qualificação de pessoal (o corpo de funcionários era composto basicamente por voluntários, o que não mais ocorre), baixa razão adulto-criança, ausência de legislação especifica e de normas básicas de funcionamento.

De acordo com ROSEMBERG ${ }^{20}$, a qualidade do atendimento das creches conveniadas raramente tem sido aval lada por especialistas ou educadores de forma continua. Assim, pouco se sabe da qualidade psicológica e educacional de seu serviço. De modo geral, são fiscalizadas pelos próprios técnicos do órgão que estabelece convênio não existindo contudo, uma avaliação global do conjunto das creches atendidas. Esta falta de avaliação também ocorre porque poucas instituições de pesquisas e poucos pesquisadores têm se interessado pelo estudo da creche. Os estudos realizados, na opinião dos autores ${ }^{20}$, informam alguma coisa sobre experiências locais, sem permitir a generalização dos resultados. Têm evidenciado que a qualidade do atendimento varia muito, mesmo nos casos de creches conveniadas com o mesmo órgão público. Essa qualidade parece depender de uma série de tutores, desde as características da instituição que criou e mantém a creche, de sua filosolia educativa, da forma como se relaciona com a população local, até da instalação material e recursos de que dispõe”20.

\section{LEGITIMAÇÃO}

O processo de legitimação das creches foi facilitado pelas reivindicações do Movimento de Luta por Creches (resolução do I Congresso da Mulher Paulista)". Estas partiram das camadas populares. levando o Estado a reconhecer sua função de guardião, responsável pela assistência à criança. A proposta desse movimento foi a criação de uma rede de creches totalmente mantida pelo Estado, com a participação da comunidade na orientação e na escolha de seus funcionários. Diferentemente do que ocorreu nos países norte-americanos e europeus, no Brasil não se questionou o conteúdo implícito da proposta educativa, desenvolvida nas creches. Para HADDAD ${ }^{11}$, "a palavra de ordem limitava-se à oposição aos depósitos de crianças. Não se discutia ainda o caráter da creche como local de socialização da criança e como local que permitisse à mulher compartilhar socialmente de sua guarda. O discurso feminista no Brasil cuidou apenas do trabalho da mulher. Não houve discussões públicas sobre maternidade, paternidade, modificações no arranjo doméstico ou na própria estrutura da organização do trabalho. A fala referia-se a uma instituição que propiciasse essencialmente a guarda". "Praticamente não houve propostas de modelos de programas educativos. De acordo com a autora”, como tema, a criança estava praticamente ausente dos argumentos apresentados no período.

Nos últimos anos, o debate sobre creches tem tido considerável avanço no país. O esforço de grupos, interessados na política pública, possibilitou a inclusão da creche na Constituição Brasileira de $1988^{4}$, como uma ampliação do direito universal à Educação, de crianças com 6 anos ou menos. Isso significa reconhecer, nela, uma instituição legítima, capaz de adquirir uma identidade própria e definir uma política específica. Além disso. dá à família o direito de compartilhar a educação da criança com o Estado. Enquanto instituição educativa deverá "concentrar-se em programas que promovam, adequadamente o desenvolvimento infantil, rompendo com o assistencialismo benevolente e com o modelo tradicional de oferecimento de cuidados maternos à criança independentemente de sua condição socio-econômica”. 
Segundo CAMPOS 6 , "pela primeira vez na história, uma Constituição do Brasil como a de 1988, faz referências a direitos específicos das crianças, além daqueles circunscritos ao âmbito do Direito da Familia. Também, pela primeira vez, um texto constitucional define claramente como direito da criança de 0 a 6 anos de idade é dever do Estado, o atendimento em creche e pré-escola (Art. 208, inciso IV). As constituições anteriores limitam-se a expressões como assistir ou amparar a maternidade e a infância. A nova carta nomeia formas concretas de garantir não só esse amparo, mas, principalmente, a educação dessa criança" (p. 9).

\section{FUNCIONAMENTO E ESTRUTURA}

O funcionamento das creches conveniadas deve ser de 10 horas diárias, durante 11 meses, sendo desejável que funcionem 12 horas diárias, sem interrupção durante o ano, com férias escalonadas, de acordo com o Documento Política de Convênios^24 SEBES, de 1991. Esse documento propõe que o pessoal, para atendimento à criança, seja proporcional ao número de crianças usuárias para cada creche.

\section{RESPONSABILIDADES DOS EDUCADORES E DAS PÁJENS}

Segundo o projeto pedagógico da SEBES de $1991^{26}$, para as creches municipais, "mais importante do que ensinar, é estimular criança a aprender, permitindo sua inserção no mundo e sua adaptação social, a partir da percepção que esta possa adquirir do mundo físico e do ser humano, construindo sua identidade e sua auto-estima. Atividades planejadas, assim como a avaliação do ambiente, dos recursos e dos objetivos, traduzem a responsabilidade dos educadores no sentido de considerar as características das crianças, como indivíduos pertencentes a determinados grupos sociais” (p. 9).

A pajem ou ADI (Auxiliar de Desenvolvimento Infantil) é contratada pelo regime da Consolidação das Leis Trabalho ${ }^{5}$, com jornada de 40 horas semanais. Tem sido vista pela FABES, como a mediadora da conversa da criança com a vida ${ }^{26}$. Cabe-lhe conhecer as necessidades e perceber, em cada momento e em cada etapa do desenvolvimento da criança, o que esta pode fazer sozinha e de que modo deve ocorrer sua intervenção. É importante estar atenta, dando à criança o tempo necessário para que compreenda seus problemas e busque soluções em cada situação. A antecipação do adulto, com respostas prontas, em nada estimula o desenvolvimento da criança que precisa adquirir seu próprio conhecimento e conquistar seu próprio espaço na sociedade.

\section{CAPACITAÇÃO DE FUNCIONÁRIOS}

Vários estudos ${ }^{2,5,7,12,15,17,20}$ têm demonstrado a importância do treinamento e a necessidade de capacitação dos funcionários de creches. Este deve oferecer condições para atender melhor às necessidades da criança. Ao planejar o treinamento, é fundamental considerar os objetivos que se pretende alcançar e, particularmente, os conhecimentos, atitudes, habilidades e práticas das pajens e dos outros funcionários, em função da responsabilidade que têm no atendimento e na educação e desenvolvimento da criança.

A avaliação sistematizada dos recursos humanos em creches é necessária, não só para corrigir intervenções inadequadas, como, também, para assegurar melhor atendimento.

Pesquisa qualitativa, realizada em 1992 pelo autor deste trabalho nas creches conveniadas da Bela Vista na cidade de São Paulo ${ }^{17}$, por meio de entrevista com diretoras, mostrou a alta rotatividade entre os funcionários, que se queixaram de baixos salários e de despreparo para as funções que exerciam, pois raramente eram treinados em serviço ou reciclados. Emergiu assim, de uma necessidade sentida, a realização do I Curso Modular sobre Crescimento e Desenvolvimento Infantil. para pajens e auxiliares de enfermagem da região ${ }^{17}$.

A necessidade de definição de uma política de recursos humanos aparece constantemente no discurso oficial de instituições de vários setores, mas, geralmente, representa apenas um conjunto de intenções que quase nunca chega à prática.

Para $\mathrm{SCHOCHI}^{23}$, freqüentemente, o trabalhador não consegue alcançar a finalidade de seu próprio trabalho. Percebe o seu trabalho apenas como uma tarefa imediata a ser cumprida e não como um trabalho coletivo, inserido no conjunto das relações sociais. Segundo o autor, toda aprendizagem precisa ser significativa para o funcionário. Deve-se então, nos treinamentos, partir do seu conhecimento anterior, trabalhar com seus valores e visão do mundo, utilizando para isso a metodologia problematizadora e discutir o processo educacional em função da prática já experimentada e dos conceitos adquiridos em relação a essa prática. Segundo PEDUZZI ${ }^{16}$, a teoria é necessária na medida em que subsidia a reflexão sobre a prática. 
Ao reconhecer a importância do papel do funcionário junto às crianças, a creche deve procurar investir nos seus recursos humanos, capacitando-os para a melhoria da qualidade da atenção dispensada.

De acordo com ROSEMBERG ${ }^{20}$. o atendimento de creche em período integral não conta com pessoal qualificado utilizando-se muitas vezes de leigos com baixo nível de escolaridade, sem nenhum curso específico de capacitação. As carreiras de profissionais de creche não foram ainda definidas e muito menos regulamentadas. Para essa autora, as crianças tem tido um atendimento relativamente eficicnte do ponto de vista de guarda, proteção e cuidados físicos mas, em geral, não têm encontrado satisfação para suas necessidades afetivas e educacionais. Isto poderia ser superado pela orientação técnica cuidadosa e preocupação constante com a formação em serviço do pessoal contratado.

A Constituição do Estado de São Pau1o ${ }^{22}$, promulgada a 5 de Outubro de 1989, Capítulo III - Da Educação o art. 248 determina que: o órgão próprio de educação do estado será responsável pela definição de normas, autorização de funcionamento supervisão fiscalização das Creches e Pré-Escolas públicas e privadas no Estado.

$\S$ único - Aos municípios, cujos sistemas de ensino estejam organizados, será delegada competência para autorizar o funcionamento e supervisionar as instituições de educação das crianças de zero a seis anos de idade.

$\mathrm{O}$ relato de experiência de uma Creche Municipal de Santana, São Paulo, feito pelo Conselho Nacional dos Direitos da Mulher ${ }^{9}$ em 1988, também falava sobre a necessidade de formação profissional das pajens, geralmente, profissionais sem formação para esse tipo de trabalho com escolaridade de $4^{\text {a }}$ série do $1^{\circ}$ grau, trazendo, na maioria, apenas a experiência do trabalho doméstico. Isso justificaria a percepção do trabalho das pajens que olhavam a criança de acordo com as suas experiências domésticas, sendo difícil a compreensão quanto às necessidades das crianças nas diferentes idades e, especialmente, quanto ao melhor processo educativo para o seu desenvolvimento. A preparação dessas profissionais para o trabalho foi feita pelas professoras e pelo pessoal ligado à saúde através de discussão em grupo e orientação individual, o que contribuiu significativamente para a mudança de atitudes pretendida. Durante dois anos houve um grande esforço no sentido de implantar novas rotinas e métodos de trabalho, o que se obteve a partir da organização da categoria. Entre as novas conquistas, as pajens das creches diretas da Prefeitura $\mathrm{Mu}-$ nicipal de São Paulo (PMSP) conseguiram redu- zir sua carga horária de oito horas para seis horas e trinta minutos diários, antiga reivindicação da categoria ${ }^{9}$.

Alguns fatos têm ocorrido nas creches paulistas e vêm comprovar a crise extremamente grave pelas quais estão passando essas instituições. O Jornal “O Estado de São Paulo”, de 14 de julho de 1993, página 10 (Cidades), relata em artigo de Ruberti, algumas situações bastante dramáticas, mas já conhecidas por todos: as creches da rede municipal não têm equipamentos, faltam funcionários, manutenção e vagas para as crianças. Na semana anterior à publicação, dois bebés haviam falecido em duas creches municipais um em São Mateus, vitima de problemas cardíacos, outro, em São Miguel Paulista morreu asfixiado, depois de regurgitar; ambas localizadas na Zona Leste. Segundo declarações de Antonio Sallim Curiati, Secretário da Família e Bem Estar Social da PMSP (gestão (1993 - 1 996), no mesmo artigo, além das 317 unidades diretas existiam nessa ocasião outras 341 unidades conveniadas em São Paulo. Juntas elas somavam aproximadamente 75 mil vagas, ou seja, tinham possibilidade de atender a apenas $20 \%$ da demanda, constituída por filhos de famílias que recebiam até quatro salários mínimos mensais. Cálculos da Secretaria demonstraram que 315 mil crianças de 0 a 6 anos, esperavam por uma vaga. “Oitenta por cento das creches, precisavam de manutenção quando assumimos a ^rde famílias que recebiam até quatro salários mínimos mensais. Cálculos da Secretaria demonstraram que 315 mil crianças de 0 a 6 anos, esperavam por uma vaga. ‘Oitenta porcento das creches, precisavam de manutenção quando assumimos a FABES. O orçamento da Secretaria, fixado em Cr\$ 4 trilhões, é insuficiente e já foram enviados à Camara pedidos para que os vereadores aprovem a readequação de verbas de Cr\$ 7 trilhões mais a suplementação de Cr\$ 5 trilhões”. O artigo prossegue citando um relatório publicado no Diário Oficial do Município, que mostrava a necessidade de reparos nas instalações hidráulicas e de saneamento em 223 unidades (creches diretas) e de troca de porias e vidraças em outras 222.

As creches também foram alvo de vandalismo, tendo sido, neste ano, registradas 120 ocorrências em delegacias de polícia por causa de depredações. Com relação aos recursos humanos, Maria Malta Campos, pesquisadora da Fundação Carlos Chagas e que trabalha com Creches desde 1975, afirmou que desde o início do ano (de 1993) mais de 150 diretoras de creches municipais foram substituidas. "As funcionárias com experiência foraram demitidas e a maioria das admitidas é despreparada para o cargo. O cargo é de confiança, não é preenchido por concurso e quando muda 
a administração serve para atender a interesses políticos. Os funcionários e as crianças pagam um preço alto até se adaptarem às mudanças". Para Curiati*, "as diretoras tem que seguir as diretrizes pedagógicas da Secretaria e as recém-admitidas precisam ser submetidas a treinamento. Quando o Partido dos Trabalhadores assumiu, também mudou as diretoras”. A baixa qualificação não é criticada apenas em relação às diretoras. As Auxiliares de Desenvolvirnento infantil (ADI ou pajens) anteriormente só precisavam ter até a $4^{\mathrm{a}}$ série (primário). Ganhavam em média Cr\$ 6 milhões (de cruzeiros) por mês nas creches diretas, salário bastanto baixo, porém maior do que recebiam a pajens das creches conveniadas na época dá publicação do artigo citado. Agora a FABES está exigindo o $l^{\circ}$ grau completo para admissão das ADIS. CAMPOS considera que, como são mal pagas, essas pessoas têm nível de vida precário e faltam muito. “'Os quadros de funcionários estão incompletos na maioria das creches, afirma a pesquisadora para o jornal. Às vezes, o número de funcionários é adequado, mas as pessoas são pouco qualificadas. A média de 100 crianças por unidade é alta. Em países desenvolvidos, há, no máximo, 60 crianças por creche. As mudanças constantes na administração, os baixos salários e a falta de equipamentos, levam a um clima de insatisfação que cria condições propícias a fatos não desejados”, diz a pesquisadora, referindo-se à morte das crianças, registradas na semana anterior.

A formação das trabalhadoras de creches só será efetiva na medida em que houver participação social dos funcionários em seus órgãos de representação (sindicatos de classe, associações e movimentos sociais), quando forem valorizados por salários justos e tiverem seus direitos respeitados.

\begin{abstract}
This work presents a bibliographical review on the development of daycare centers and their role along history, specially in Brazil. It also discusses the difficulties that the day care centers have been facing, including those related to the training of their staff, mannly composed of women.
\end{abstract}

Key-Words: daycare centers, capacitation, working women.

\section{REFERÊNCIAS BIBLIOGRÁFICAS}

1 AINSWORTH, M. D. S. Pesquisas sobre os efeitos prejudiciais da privação. In: Bowby, J. Cuidados maternos e saúde mental. São Paulo, Martins Fontes, 1981. p. 174-90.

2 BASSOFF, B. Z; WILLIS, W. O. Requiring formal training in preventivo health practices for child day care providers. Public Health Rep. 106: 523-9, 1991.

3 BOWLBY, J. Cuidados maternos e saúde mental. São Paulo, Martins Fontes, 1981.

4. BRASIL Constituição 1988. Constituição: Repúb1ica Federativa do Brasil. Brasília, Centro Gráfico do Senado Federal, 1988.

5. BRASIL. Leis, etc. Consolidação das leis do trabalho. Org. Juarez Oliveira, São Paulo, Saraiva, 1993.

6. CAMPOS, M. M.; ROSEMBERG, F.; FERREIRA, I. M. Creches e pré-escolas no Brasil. São Paulo, Cortez/Fundação Carlos Chagas, 1993.

7. CARVALHO FILHO, B. Nota sobre o papel dos educadores que atuam junto às crianças que vivem na rua. Cad SITRAEMFA 2: 18-9, 1991.
8 CONFERÊNCIA NACIONAL DE SAÚDE, 8^a Brasilia, 1986. Anais. Brasília, Centro de Documentação do Ministério da Saúde, 1987.

9 CONSELHO NACIONAL DOS DIREITOS DA MULHER. Creche urgente: relato de experiencias. Brasilia, 1988 (série de Manuais sobre Creche, 7).

10 HADDAD, L. A relação creche-família: relato de uma experiência. Cad Pesq. 60: 70-8, 1987.

11 HADDAD, L. Creche: reflexões sobre uma trajetória. In: Costa, A. de O.; Bruschini, C., org. Rebeldia e submissão: estudos sobre a condiçãofeminina. São Paulo, Fundação Carlos Chagas/Vértice, 1989. p. 101-20.

12. HUSBY, R. D. Child day care for welfare mothers. Contents, 19(4): 420-5, 1974.

13. NOGUEIRA, D. P. Absenteismo - doença, aspectos epidemiológicos. São Paulo, 1980. [Tese de Livre-Docência - Faculdade de Saúde Pública da USP].

14. NOGUEIRA, D. P. Trabalho de mulheres. Rev. Bras. Saúde Ocup. 10 (38): 12-6, 1982.

15 OLIVEIRA, Z. DE M.R. de; FERREIRA, M. C. R. Propostas para o atendimento em creches no municipio de São Paulo. Cad. Pesq. S.P. 56: 39-65, 1986.

\footnotetext{
* Jornal “O Estado de São Paulo”, de 14 de julho de 1993, pág. 10 (Cidade).
} 
16 PEDUZZI, M. Capacitação de pessoal auxiliar em saúde mental: reflexões a partir da experiência de um centro de saúde escola. Saúde Deb. 36:66-72, 1992.

17 PELICIONI, M. C. F. Pesquisa qualitativa com creches conveniadas do bairro Bela Vista, São Paulo. Rev. Bras. Saúde Esc. 2(3/4): 185-92 1992.

18 PEREZ, F. R. Aproximación a una geografia de la infância: estúdio socio-espacial de las guardarias infantiles en el Distrito de San Blas de Madrid. Rev. Int. Sociol. 42: 821-44, out dic. 1994.

19 ROSEMBERG, F. O movimento de mulheres e a abertura política no Brasil: o caso da creche. Cad Pesq. 51: 73-9, 1984.

20 ROSEMBERG, F.; CAMPOS, M. M.; PINTO R. P. Creches e pré-escolas: década da mulher. S. Paulo, Nobel/Conselho Estadual dá Condição Feminina (CECF), 1985.

21 SAMPAIO, V.R. C. Creche: atividades desenvolvidas com a criança. Rio de Janeiro, Ed. Brasileira de Medicina,1984.

22 SÃO PAULO (Estado). Constituição 1989 Constituição do Estado de São Paulo. Diário Oficial do Estado de São Paulo. São Paulo, 6 out., 1989 [Encarte]
23 SCHOCHI, M. J. Contribuição ao estudo da prátic. dos trabalhadores em saúde: análise de caso de um Centro de Saúde de Ribeirão Preto, São Paulo. Rio de Janeiro, 1989. [Dissertação de Mestrado - Escola Nacional de Saúde Pública

24 SECRETARIA MUNICIPAL DO BEM ESTATAR SOCIAL. Supervisão Geral de Planejamento e Controle. Política de convênios. São Paulo PMSP/SEBES, 1991.

25 SECRETARIA MUNICIPAL DO BEM ESTAR SOCIAL. Supervisão Geral de Planejamento e Controle. Política de creche: ações educativas e preventivas de saúde. São Paulo, PMSP/SEBES, 1991.

26 SECRETARIA MUNICIPAL DO BEM ESTATAR SOCIAL. Supervisão Geral de Planejamentc e Controle. O projeto pedagógico nas creches municipais. São Paulo. PMSP/ SEBES, 1991.

27. SILVA, I. M. da; SILVA, A. A. da; CHIACHIO N. B. O estatuto da criança e do adoles cente e a questão da municipalização. São Paulo, SITRAEMFA/CBIA, 1991. (Cadernos Populares, 5).

28. SPTTZ, R. A. O primeiro ano de vida. $3^{\mathrm{a}}$ ed. São Paulo, Martins Fontes, 1983.

Recebido em: 04/02/96 Aprovado em: 02/04/96 